\title{
Dynamic Essences: Absolute, Prospective, Retrospective, and Relative Modalities
}

Błażej Skrzypulec

Polish Academy of Sciences,

Warsaw, Poland

e-mail: blazej.skrzypulec@gmail.com

Pawet Rojek

Jagiellonian University, Krakow, Poland

e-mail: pawel.rojek@uj.edu.pl

\begin{abstract}
:
Essential properties are usually thought as properties that things must always possess, whereas accidental properties are considered as changeable. In this paper, we challenge this traditional view. We argue that in some important cases, such as social or biological development, we face not only the change of accidents, but also the change of essences. To analyze this kind of change we propose an alternative view on the relations between the modalities and time. Some properties might be necessary or possible for a thing in a classical sense throughout its existence, whereas others might be necessary or possible only for some restricted periods. We distinguish therefore absolute, prospective, retrospective, and relative modalities. As we argue, these non-classical concepts of modality are useful in analysis of some puzzling case of seemingly changing essences.
\end{abstract}

Keywords: essentialism, modality, necessity, essential change.

\section{Introduction}

Usually essences are thought to be necessary and thus unchangeable. Essential properties of things are considered to be properties that things must possess, whereas accidental properties might or might not be possessed. The modal status of properties entails their relation to time. Necessary properties are properties that things always have, whereas contingent properties might change over time. Things can gain some new accidents, and can lose some old ones, but their essences remain the same. We would like to challenge this traditional view. We believe that in some cases it is possible to speak not only about changing accidents, but also about changing essences. It seems that 
in such phenomena as development or decline things might change their modal properties. Something that was possible in one stage of a process might become impossible in another, and conversely, something necessary at one time might turn out to be contingent in another. In other words, in some cases essences might turn into accidents and accidents might become essences. The standard view on the relations between essences, modalities, and time, which excludes such transformation, should therefore be revised.

It is clear that the classical concept of essence involves permanence in time. Though Aristotle's notorious expression denoting essence to ti en einai literally means "the what it was to be", it was generally understood as "the what it $i s$ to be", where "is" was thought to be timeless [14]. Essence was therefore traditionally thought as a property or properties belonging to a thing during all its existence. If $\mathrm{P}$ is essential property of $x$, then $x$ cannot gain and lose $\mathrm{P}$, but must possess it all the time it exists. The opposite, however, does not hold. Some accidents might belong to a thing for all its time, but this does not make them essences. Porphyry in his commentary on Aristotle's Categories gave famous examples: being black, for ravens, and risibility, for a human being [16, p. 12]. These properties, according to classical view, were not essential, even if were possessed by ravens and man throughout their whole life. Permanence was therefore thought as necessary, though not sufficient condition of essentiality.

This kind of link between essentiality and permanence has been strengthened by modern modalism, that is a view connecting essentiality with necessity. In this account essential properties are identified with those which are necessary for an object. The concept of necessity even more overtly involves permanence. If $\mathrm{P}$ is necessary property of $x$, then obviously $x$ possesses it whenever exists. Modalism has been famously criticized by Kit Fine [8]. He argued that necessity and essentiality differ not only in their intension, but also extensionally: there are necessary properties which can hardly be recognized as essential ones. Mathematical necessary truths for instance are formally entailed by the existence of Socrates, but do not constitute his essence in any reasonable sense. Nevertheless, Fine and his followers, though argued that necessity is not a sufficient condition of essentiality, have never doubted that it is its necessary condition (see [8, p. 4]; [22, p. 211]. Being necessary does not entail being essential, but essentiality entails necessity. Since classical necessity entails permanence in time, it means again that essences are permanent.

Indeed, it seems plausible that permanent or necessary (in classical sense) properties of things are not always essential for them. The dogma, which we want to challenge here, however says the opposite, namely that essential properties are always permanent or necessary (in classical sense). This claim seems to be shared by all debating parties. We believe that the criticism of the modalism should be extended. Modalism claims that classical necessity is both sufficient and necessary condition of essentiality. It critics argued that it is not sufficient, we believe that it is also unnecessary. In our view, the concept of essence might involve many different kinds of necessity, not the classical one. Loosening of the link between essence and necessity makes a space for the concept of changing nature. Therefore, in this paper we would like to sketch a conceptual framework for new combinations of essentiality and time. We would like to distinguish a few possible concepts of essences. Some properties might be necessary for a thing throughout its existence, whereas others might be necessary only for some periods. Thus, apart from classical absolute essences there are also non-classical time-relative types. It seems that the traditional view is only a particular case of a more general and more dynamic stance. It turns out that the concept of essence might be connected with many different concepts of necessity. The classical necessity, i.e. entailing permanence, is not necessary for being essential. It is not only insufficient, as was argued by critics of modalism, but also unnecessary condition for essentiality.

First, in Section 2, we would like to point out some puzzling examples from various fields, which highlight the need to reconsider the standard view on essences. The simplest case is taken from sociology; more complicated cases are borrowed from theology and biology. All these case pose obvious difficulties for a classical views which do not allow changing essences. These examples, as we argue, cannot be also easily discussed in a simple framework of possible worlds. Second, in order to analyze these puzzling cases, we distinguish in Sections 3 and 4 four concepts 
of modality: absolute, prospective, retrospective, and relative, which lead to various concepts of essence. We define these concepts using a logical framework generally inspired by a branching approach to time and modality (see [21], [13] for general overview). We do not however stick to any particular version of this well-developed theory. Rather, we use some of its concepts and intuitions to construct a very simple framework needed to our purposes. Finally, in Section 5, we attempt to use that framework to interpret non-classical cases discussed in Section 2. We believe that the proposed temporal extension of classical essentialism might help in clarifying intuitions concerning modalities changing over time.

\section{Three Modal Puzzles}

Now we would like to introduce a few examples that show that in some cases it is plausible to speak about changing essences. Things can undergo deep ontological changes, which are much more radical than simple accidental modification, but this does not lead to the destruction of these things. This kind of change is neglected in the classical view.

\subsection{Internalization}

The first and the simplest example comes from sociology. Peter Berger and Thomas Luckmann investigated the complex process of the construction of social reality. Briefly, it consists of three fundamental stages: externalization, objectification, and internalization. People constantly define their own reality, afterwards treat it as independent, and finally transmit it to their children. The way people act is fundamentally contingent. We could choose, fix, and transmit completely different ways of behaving. Nevertheless, in the process of internalization the results of occasional human activity obtain the independent status of inevitability:

The child does not internalize the world . . . as one of many possible worlds. He internalizes it as the world, the only existent and only conceivable world, the world tout court. . . Primary socialization thus accomplishes what (in hindsight, of course) may be seen as the most important confidence trick that society plays on the individual - to make appear as necessity what is in fact a bundle of contingencies [3, pp. 154-5].

In other words, in the process of internalization some accidental and external characteristics, such as those that are default ways of acting in a given society, become essential and internal for individuals. If we were born and brought up in a different society, we would think and act in different ways, but once we successfully pass through the process of primary internalization in a determined society, we treat some particular ways of thinking and acting as fairly natural and in fact necessary.

Berger and Luckmann argue that primary socialization is in principle irreversible. The world internalized in this process is so deeply entrenched in consciousness that one cannot simply abandon it or distance oneself from it:

Our analysis suggests that such distance is only possible with regard to realities internalized in secondary socialization. If it extends to the realities internalized in primary socialization, we are in the domain of what American psychiatry calls "psychopathy," which implies a deficient formation of identity [3, p. 230].

This means that the image of the world received in early childhood constitutes the very essence of human identity. The results of secondary socialization in school or a place of work are perceived as much more accidental. One can learn new things or change social roles without undermining one's fundamental sense of reality. 
This sociological example of changing essence differs from classical cases, not only - as we suggested - because the essence changes in this case, but also because it is somehow subjective. Social reality depends on the definitions accepted by the members of a society. To be real in a social world is to be taken as real. Moreover, the loss of acquired essence does not literally lead to the cessation of the individual existence. The loss of the primary image of the world presumably leads to psychopathy, but not necessarily to suicide. This is the exact the point of difference between the sociological example and the two following cases taken from theology and biology, where essences are thought to be perfectly objective.

\section{2. Augustine}

The second example is the most ancient and venerable, since it comes from St Augustine. He suggests in a few passages that the religious development of humankind, starting with creation of human beings and ending in their salvation, might be seen as a series of transformations of human nature. In the first place, humankind in Eden could do things that would be impossible for them in the final stage, in heaven. Augustine writes:

The first freedom of the will was therefore to be able not to sin; the final freedom will be much greater: not to be able to sin. The first immortality was to be able not to die; the final immortality will be much greater: not to be able to die. The first power of perseverance was to be able not to abandon the good; the final happiness of perseverance will be not to be able to abandon the good. The final goods will be better and more powerful [1, p. 214].

According to Augustine, at the beginning of creation human beings could sin or not sin (posse peccare et posse non peccare), whereas at the end of salvation humankind will not be able to sin (non posse peccare).

Augustine used this idea of modal transformation to clarify the sense of the Fall and the Redemption. Due to Adam's original sin humankind lost the possibility of not sinning (posse non peccare) and was left with the mere possibility of sinning (posse peccare). After the Fall human beings could not not sin. The Redemption fortunately restored this corrupted human nature. Due to Christ's actions, human beings again acquired the possibility of not sinning (posse non peccare). Finally, our future Salvation will consist in the last irreversible modal change, which will exclude the possibility of sin [1, pp. 213-5].

Regardless of the subtlety of these theological matters, it seems that, for Augustine, human nature is substantially changeable. It allowed some possibilities at first that afterwards were apparently excluded. The essence of a human being was therefore thought to be dynamic, not static. This view obviously calls for a revision of the classical concept of essence.

\subsection{Jellyfish}

A similar example of a changing nature might be found in biology. We would like to focus on the lifecycle of a jellyfish. Most jellyfish start their existence in a larval form, after some time transform into a stationary polyp, and later undergo the final transformation, which results in an adult medusa. Such a description suggests the presence of some modal properties. First, it seems that a jellyfish has to possess the property of "being a larva" for some time at the beginning of its life. Second, it is possible for a jellyfish to stop being a larva, while still continuing its existence as a polyp and, after some time spent in a polyp stage, it is also possible for it to stop being a polyp and become an adult medusa. Third, after reaching the adult stage it is no longer possible for a jellyfish to stop being an adult medusa and yet continue its existence.

However, there are exceptions form the above "standard" pattern: 
[A] unique case of ontogeny reversal has been reported by Bavestrello et al. (1992), in which newly released, sexually immature medusae of Turritopsis nutricula McCrady, 1859, regressed, settled onto a substrate, and gave rise to stolons and hydroid colonies $[15$, p. 302].

It turns out that exemplars of Turritopsis nutricula jellyfish are able to return to the polyp stage even after reaching adulthood. Because the cycle of being an adult medusa and reverting to a polyp can - at least in some perfect environmental conditions - go on ad infinitum, the Turritopsis nutricula jellyfish does not have a limited life span. Within this peculiar life cycle it is no longer impossible to continue existence despite losing the property of being an adult medusa, due to the fact that existence may be continued in a form of a polyp.

This biological example shows that variations in modal properties occur both within the life cycle of a single jellyfish and between the life cycles of jellyfish belonging to different species. Jellyfish with "standard" life cycles may acquire the modal property of being an adult medusa, which then cannot be lost as long as the jellyfish lives. Because of this, their modal properties can change during their lifetime. The property of being an adult medusa does not have the same modal status in the life cycle of Turritopsis nutricula, as these jellyfish can live after losing this property. Because of this, we may speak about modal differences between the life cycles of various species. Modal properties like "being a larva", "being a polyp", and "being an adult medusa" seems to be good candidates for essential properties as they determine what an entity is at different stages of its development [6], [7]. However, their status cannot be characterized within a theory that only allows for essential properties that have to be possessed at all moments of an object's existence.

Now, it seems that all these examples challenge the classical essentialism. Apparently in some cases things can change their essences. During the process of ontological development things lose some former possibilities and gain new ones. As we saw, this process might be either irreversible, as in the cases of primary socialization, final salvation, and adultness of ordinary jellyfish, or reversible, as in the cases of secondary socialization, original sin, and becoming an adult Turritopsis nutricula. These processes can hardly be described as merely accidental changes. We find it perfectly plausible to say that these things change their modal properties, so they also change their essences. Something that was possible or necessary at one stage becomes necessary or possible in another. This is exactly what might be called a change of essence.

\section{Four Kinds of Modal Properties}

Now we would like to sketch a general conceptual framework for expressing the modal intuition of dynamic essences. First of all we would like to generalize the previous puzzling examples and distinguish a few kinds of modal properties. Because of that, in the next section, we shall propose a conceptual scheme inspired by a branching approach to time.

Let us consider some episodes from the life of the entity named "Kant". The existence of Kant started at a moment $\mathrm{t}_{0}$. At that time Kant was identical to an embryo and so did not possess a brain. However, this situation only lasted until a later moment $t_{\mathrm{A}}$, at which Kant developed a human nervous system. Let us focus first on two of Kant's properties: the property of having a brain and the property of being an embryo.

Having a brain can plausibly be considered an essential property of Kant. First, after moment $\mathrm{t}_{\mathrm{A}}$ one important answer to the question "What is Kant?" consists in stating that Kant is a brain-possessing creature. Second, having a brain determines much of the Kant's other properties, and facts about Kant's brain may be used in explaining his actions [5]. Third, and the most important, having a brain seems to involve some modal aspect. While Kant does not possess brain at every period of his life, after moment $t_{\mathrm{A}}$ it is impossible for Kant to lose his brain without ceasing to exist (it is a so-called "phasal property"; see [2], [10]).

Being an embryo also seems to be an essential property of Kant (see [6, p. 188] for a similar example). It also determines what Kant was in the early stages of his development. Similarly to the 
case of having a brain, being an embryo is not a characteristic that Kant possessed for his whole life: at a certain moment $t_{B}$ Kant lost this property. Despite this, the property of being an embryo also possesses a modal component. It seems that at moments earlier than $t_{B}$ it was impossible for Kant to not be an embryo.

These two examples suggest that Kant both gained and lost essential properties during his lifetime: at $t_{\mathrm{A}}$ he gained the property of having a brain, while at $\mathrm{t}_{\mathrm{B}}$ he lost the property of being an embryo. We may also consider other properties, which could be possessed for some time and in some broad sense might be called essential. For instance, being a philosopher is neither a property that Kant had at all moment of his life, nor a property that could not be lost after obtaining it. In such a case, is there a sense in which being a philosopher may be an essential, and so a necessary property of Kant? We may imagine that for Kant being a philosopher, a property gained by him at some moment $t_{C}$, was a deeply internalized aspect of his personality, which could not be lost in a short period of time, but only due to a lengthy process in which Kant's personality would be gradually transformed (see [19] for a similar intuition). If this is right, then we can state that it would have been impossible for Kant to stop being a philosopher during a certain, finite period of time after $t_{C}$. In other words, all temporally shorter ways of losing the property of being a philosopher would have led to the end of Kant's existence.

Of course, apart from the above three peculiar kinds of essential properties that can be gained or lost (or both) in time, Kant may be also described as possessing more standard ones. Probably being a homo sapiens serves as a plausible example of an essential property that Kant possessed at every moment of his existence, which he could not exist without.

It seems therefore that there are different types of essential properties, some of which may be gained or lost during the life history of an object. All these essential properties involve a modal component, since it may be stated that they are in some way necessary for an object that possess them.

It should be noted that the further considerations do not rely on our accepting the story about Kant as entirely true. One may doubt whether Kant really existed before the development of his brain or whether it is possible to internalize the role of philosopher so strongly that it cannot be rapidly lost. What is important is to observe that somebody may rationally accept the above story about Kant and his essential properties. Thus, we need a theory to explain the meaning of statements attributing different types of essentiality, and so different types of necessity, to Kant's properties.

Of course, one may simply reject the above problem by stating that the properties that an object cannot lose but can lack at some periods of its life, like "having a brain", are not necessary properties and so are not essential [18]. From this perspective only properties that an object cannot lack, like "being a homo sapiens", deserve the status of being essential. While such position is internally coherent, we believe that it is misguided from a methodological point of view. According to our pre-theoretical intuitions objects may have some special properties that determine what a given object is and are such that object in some sense "has to" possess them. These properties may be called "essential" and the role of a philosophical theory is to explain more precisely what the essentiality of properties means in accordance with basic intuitions. It seems to us that properties like "having a brain" in the story about Kant can be intuitively regarded as essential.

\section{Modal Histories Framework}

Now we would like to propose a simple formal framework for dynamic essences. First, we will introduce two sets - one representing time, and one representing qualities - then we shall combine them to arrive at the concept of a modal history of an object, which serves as a basis for further definitions of various kinds of necessities determining different types of essential properties.

The first set, $\mathrm{T}=\left\{\ldots, \mathrm{t}_{0}, \mathrm{t}_{1}, \ldots\right\}$, is an infinite set of moments linearly ordered by the asymmetric (and so irreflexive) but transitive relation is later than. In addition, moments $t_{\mathrm{i}}$ and $\mathrm{t}_{\mathrm{k}}$ are successors iff $t_{k}$ is later than $t_{i}$, but there is no moment later than $t_{i}$ and earlier than $t_{k}$. 
The second set, $\mathrm{Q}=\{\mathrm{A}, \mathrm{B}, \mathrm{C}, \ldots\}$, is a nonempty set whose elements are maximal sets of properties (MSP), excluding properties concerning an object's existence at a particular moment (e.g., "exists at $t_{1}$ "). A set of properties is maximal if and only if for any property $F$, either $F$ or $\sim F$ belongs to the set.

A Cartesian product $\mathrm{Q} \times \mathrm{T}$ is a nonempty set of $M S P$ at times: $\mathrm{QT}=\left\{\ldots,\left\langle\mathrm{A}, \mathrm{t}_{1}\right\rangle,\left\langle\mathrm{B}, \mathrm{t}_{2}\right\rangle, \ldots\right\}$. Now, by referring to the set QT, the crucial notion of the proposed framework, modal history of an object $x$, may be characterized.

The modal history of an object $x, \mathrm{MH}(x)$, is a structure composed of MSP at times, containing all MSP at times that $x$ can have during its existence and only those MSP at times. For example, if $\left\langle\mathrm{A}, \mathrm{t}_{1}\right\rangle$ does not belong to the $\mathrm{MH}(x)$, then the entity $x$ cannot exist at moment $\mathrm{t}_{1}$ in a way characterized by A. Further, in the context of modal histories MSP at times will be called points of a modal history.

Because a modal history is a structure, there is a relation organizing the points of a modal history. More precisely, a relation is needed that describes how the properties of an object can change in subsequent moments. This relation cannot simply be the is later than relation connecting moments, as in this case all points containing earlier moments would be connected with all points that contain later moments. Such a solution wrongly excludes modal histories which, for example, includes points $\left\langle\mathrm{A}, \mathrm{t}_{1}\right\rangle,\left\langle\mathrm{B}, \mathrm{t}_{1}\right\rangle$, and $\left\langle\mathrm{C}, \mathrm{t}_{2}\right\rangle$, but in which an object can be as it is characterized by $\mathrm{C}$ at $\mathrm{t}_{2}$ only if at the previous moment it possessed properties included in $\mathrm{A}$ (and not those included in $\mathrm{B})$.

We propose the introduction of an asymmetric and intransitive relation of modal binding that may connect points containing subsequent moments. If some points $\left\langle A, t_{1}\right\rangle$ and $\left\langle B, t_{2}\right\rangle$ stand in such a relations, it means that if an object possesses A-properties at $t_{1}$, then at $t_{2}$ it can possess Bproperties. What is more, we may define that a point $k$ of a modal history is in the asymmetric and transitive relation of being further $(<)$ than point $g$ of this modal history iff there is a chain of modally bounded points whose first element is $g$ and last is $k$. If one point is further than another, then there is a pattern of changes that can lead from properties possessed at the earlier point to properties possessed at the further point.

A modal history can have a branching shape. Let us consider a very simple example of such a history (lines represent modal binding relations) (Fig. 1):

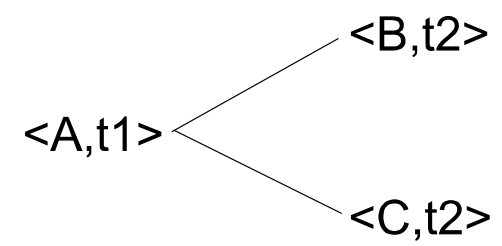

Fig. 1 A simple branching modal history.

According to the above diagram, an object can only exist at two moments: $t_{1}$ and a successive moment $t_{2}$. At moment $t_{1}$ it can exist if and only if it has properties belonging to the maximal set $A$. However, at $t_{2}$ it can exist in two different ways: having properties belonging to the maximal set $\mathrm{B}$ or having properties belonging to the maximal set $\mathrm{C}$.

Up to this point, the framework of modal histories may seem analogous to models of branching-time, which describe tree-like structures composed of moments ordered by a is later than relation [21], [13]. Indeed, similarly to the branching-time approach, the properties of the $R$ relation and the ordering of moments in the set $\mathrm{T}$ forbid backward structures (e.g., in which $\mathrm{t}_{1}$ is later than $\mathrm{t}_{2}$ ) and reflexive structures (e.g., in which $\mathrm{t}_{2}$ is later from itself).

However, branching-time models usually put additional restrictions on the permitted structures. Most notably, in standard branching models structures can branch only towards the future, but not into the past. More formally, it is assumed that if $t_{k}$ is later than $t_{i}$ and $t_{k}$ is later than $t_{j}$, then $t_{i}=t_{j}$ or $t_{j}$ is later than $t_{i}$, or $t_{i}$ is later than $t_{j}$. Because of this, the structures described in branching-time models may intuitively be called "tree-like", or described as possessing many "branches" resulting from a single "trunk". However, if we look for a framework describing the 
ways in which an object can be at earlier and later moments, an analogous constraint should not be postulated in the case of modal histories. Let us consider another very simple modal history (Fig. 2):

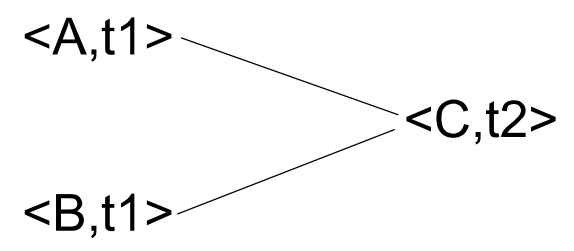

Fig. 2 A modal history that branches towards the past.

According to that diagram, an object at $t_{1}$ can exist as having properties belonging to the maximal set $\mathrm{A}$ or as having properties belonging to the maximal set $\mathrm{B}$. However, in the successive moment $\mathrm{t}_{2}$ it can exist only as having properties belonging to the maximal set $\mathrm{C}$. The presence of such "modal bottlenecks" cannot be a priori rejected; in fact they may be quite popular, and so modal histories that branch towards the past should be permitted. Metaphorically speaking, modal histories often do not resemble well-groomed trees, but rather the rhizomes beloved of postmodern thinkers.

In addition, in the characterization of modal histories it is not even assumed that for any two points of the history, $\mathrm{g}_{1}$ and $\mathrm{g}_{2}$, it is the case that $\mathrm{g}_{1}<\mathrm{g}_{2}$ or $\mathrm{g}_{2}<\mathrm{g}_{1}$. In other words, a single modal history may be composed of unconnected "branches". Let us consider a simple modal history once more (Fig. 3):

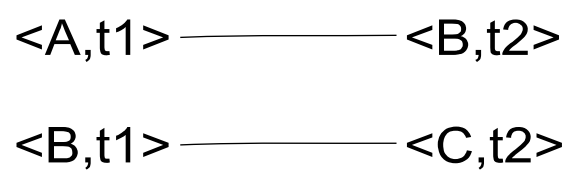

Fig. 3 A modal history compose of two unconnected branches.

An object with the modal history illustrated by the above diagram can exist at $t_{1}$ as having properties belonging to the maximal set $\mathrm{A}$ or as having properties belonging to the maximal set $\mathrm{B}$. What is more, at $\mathrm{t}_{2}$ it can exist as having properties belonging to the maximal set $\mathrm{B}$ or as having properties belonging to the maximal set $\mathrm{C}$. However, if it has properties belonging to the maximal set $\mathrm{A}$ at $\mathrm{t}_{1}$, than at $\mathrm{t}_{2}$ it can only has properties belonging to the maximal set $\mathrm{C}$, and if at $\mathrm{t}_{1}$ it has properties belonging to the maximal set $\mathrm{B}$, then at $\mathrm{t}_{2}$ it can only have properties belonging to the maximal set D. Again, it seems that there is no a priori reason to exclude objects with such modal histories and so histories composed of unconnected branches should be allowed (see [5, pp. 121-23] and the criticism in [11]).

Having characterized the notion of a modal history of an object $x$, we may now show how it can be used in explaining the difference in modal status of Kant's various essential properties. The framework of modal histories allows us to express various intuitively true modal statements concerning Kant. For example, it seems plausible that it would have been possible for Kant to start his life with properties different to those that he actually possessed. In such a case, in Kant's modal history there would be at least two minimal points that have the same moment but different MSP (see Fig. 2).

Some more extravagant modal claims concerning Kant correspond to some structures of modal histories. For instance, one may claim that it was possible for Kant to have been born in Berlin and that in this case his life would have been completely different (he was actually born in Königsberg). If this is the case, then Kant's modal history is composed of at least two unconnected branches (see Fig. 3). The minimal point of one of these branches has MSP with "being born in Berlin" as its element, while the minimal point of the second one has MSP with "being born in Königsberg. 


\section{1. Absolute Necessity}

Let us now consider how the framework of modal histories may help in explicating statements concerning the necessity of essential properties. We start with a classical concept of necessity, then we shall define non-classical cases. The classical, absolute concept would be referred to as $\square^{A}$, the "absolute necessity".

As stated above, "being a homo sapiens" seems to be an essential property of Kant. What is more, this property was possessed by Kant at every moment of his life and it was impossible for him to exist while lacking this property. In terms of a modal histories framework it can be stated that at each point of Kant's modal history "being a homo sapiens" belongs to MSP related to that point, or simpler, that at each point of his modal history Kant possesses "being a homo sapiens". Because Kant's modal history contains all "MSP at times" that Kant could have during his existence, the above statement expresses the idea that there would have been no possibility of Kant existing without being a homo sapiens.

This type of necessity can be called "absolute necessity" and defined as follows:

(D1) At any point $\mathrm{g}_{\mathrm{i}}$ belonging modal history of an object $\mathrm{x}(M H(x))$ it is absolutely necessary for an object $\mathrm{x}$ to possess a property $F\left(\square^{A} F\left(g_{i}\right)\right)$ iff at every point belonging to $M H(x)$ the object $\mathrm{x}$ possesses $F$.

$\forall_{g_{i} \in M H(x)}\left(\square^{A} F\left(g_{i}\right) \leftrightarrow \forall_{g_{k} \in M H(x)} F\left(g_{k}\right)\right)$

Analogously, the notion of "absolute possibility" may be defined by stating that at some point it is absolutely possible for an object to posses $\mathrm{F}$ if and only it has $\mathrm{F}$ at some point of its modal history:

(D2) At any point $\mathrm{g}_{\mathrm{i}}$ belonging $\mathrm{MH}(\mathrm{x})$ it is absolutely possible for an object $\mathrm{x}$ to possess property $F\left(\diamond^{A} F\left(g_{i}\right)\right)$ iff there is a point belonging to $M H(x)$ that $\mathrm{x}$ possesses $F$ at this point.

$$
\forall_{g_{i} \in M H(x)}\left(\diamond^{A} F\left(g_{i}\right) \leftrightarrow \exists_{g_{k} \in M H(x)} F\left(g_{k}\right)\right)
$$

As it is easy to see, by considering the above definitions, that if at some point of a modal history it is absolutely necessary for an object to possess $\mathrm{F}$, then at this point it is also absolutely possible for an object to possess F. What is more, if at some point it is absolutely necessary for an object to possess $\mathrm{F}$, then at every point of its modal history it is absolutely necessary to possess $\mathrm{F}$. The same goes for absolute possibility: if it is absolutely possible to possess $\mathrm{F}$ at some point, then at all points it is absolutely possible to possess $\mathrm{F}$.

In the case of Kant's modal history, at each point Kant possesses "being a homo sapiens" and so at each point it is absolutely necessary for him (and so also absolutely possible) to be a homo sapiens. Now we can easily see that the necessity of another of Kant's essential properties, "having a brain", cannot be absolute necessity. It is not the case that Kant possesses "having a brain" at every point of his modal history, since at some points, at least those corresponding to the actual early phase of his development, he lacks this attribute.

\subsection{Prospective Necessity}

There were some moments in the actual life of Kant at which he did not have a brain. What is more, there are possible histories of Kant's life in which his life ended very early such that he did not have a brain at all. The necessity of "having a brain" for Kant arises from the fact that after developing a brain it is no longer possible for Kant to lose a brain and continue to exist. While there may be problems with characterizing such necessity in terms of possible worlds, it can easily be done within the framework of modal histories. Kant possesses a brain in a necessary way at some point of 
his modal history, because at every further point he possesses the property of having a brain. This type of necessity can be called "prospective necessity" and defined as follows:

(D3) At any point $\mathrm{g}_{\mathrm{i}}$ belonging to $\mathrm{MH}(\mathrm{x})$ it is prospectively necessary for $\mathrm{x}$ to have a property $F$ $\left(\square \rightarrow F\left(g_{i}\right)\right)$ iff for every $\mathrm{g}_{\mathrm{k}}$ belonging to $M H(x)$, if $\mathrm{g}_{\mathrm{k}}$ is further than $\mathrm{g}_{\mathrm{i}}$, then object $\mathrm{x}$ possesses $F$ at $g_{k}$.

$\forall_{g_{i} \in M H(x)}\left(\square^{\rightarrow} F\left(g_{i}\right) \leftrightarrow \forall_{g_{k} \in M H(x)}\left(g_{i}<g_{k} \rightarrow F\left(g_{k}\right)\right)\right)$

The notion of prospective necessity is a counterpart of the temporal logic operator G ("It will always be the case that ...", [17, p. 13]), where Gp is true at some moment if and only if $p$ is true at all later moments.

Analogously, a notion of "prospective possibility" can be defined:

(D4) At any point $\mathrm{g}_{\mathrm{i}}$ belonging to $\mathrm{MH}(\mathrm{x})$ it is prospectively possible for $\mathrm{x}$ to have a property $F$ $\left(\diamond^{\rightarrow} F\left(g_{i}\right)\right)$ iff there is $\mathrm{g}_{\mathrm{k}}$ belonging to $\mathrm{MH}(x)$ such that $\mathrm{g}_{\mathrm{k}}$ is further than $\mathrm{g}_{\mathrm{i}}$ and object $\mathrm{x}$ possesses $F$ at $g_{k}$.

$\forall_{g_{i} \in M H(x)}\left(\diamond \rightarrow F\left(g_{i}\right) \leftrightarrow \exists_{g_{k} \in M H(x)}\left(g_{i}<g_{k} \wedge F\left(g_{k}\right)\right)\right)$

The above definitions entail that prospective possibility follows from prospective necessity. ${ }^{1}$ In addition, if at some point it is prospectively necessary for an object to have $\mathrm{F}$, then also it is prospectively necessary to have $\mathrm{F}$ at all further points.

If our modal intuitions about "having a brain" and Kant are correct, then in the modal history of Kant there is a point at which it is prospectively necessary, but not absolutely necessary, for him to have a brain. In fact, a stronger statement also seems plausible: that "having a brain" cannot be possessed by Kant in any weaker sense than that specified by prospective necessity. Speaking more precisely, if at some point $g_{i}$ belonging to Kant's modal history Kant possesses "having a brain", then at $g_{i}$ it is prospectively necessary for Kant to possess "having a brain". Perhaps there are more properties like having a brain, properties of which it is true that if they are possessed, they are possessed prospectively necessarily.

The notion of prospective necessity is weaker than absolute necessity. If at some point it is absolutely necessary to possess $\mathrm{F}$, then at this point it is prospectively necessary to possess $\mathrm{F}$, but not conversely. Because of this, at some points of Kant's modal history it can be prospectively necessary for him to possess a brain, while it may still be true that he does not have a brain at every point. While there is a form of necessity connected with the property of having a brain, it is a different type to that exemplified by the absolutely necessary "being a homo sapiens". "Having a brain" is a candidate for an essential property that can be gained during an object's history: an object cannot lose it, but it can lack this property at some points of its existence.

One may ask, whether the notion of prospective necessity, and subsequent notions of retrospective and relative necessities, can be expressed in the more usual framework of possible worlds. We believe that it can be done, in a certain version of such framework, but we prefer to use the proposed modal histories framework as it seems to rests on weaker assumptions. If a necessary property of an object is defined as a property that on object has in all possible worlds in which it exists [20], [23], then the notion of prospective necessity cannot be formulated. This point can be demonstrated by considering the property of having a brain. Unfortunately, it is not the case that Kant has a brain at some moment in every possible world in which he exists, because in some possible worlds he died in the very early stages of development. What is more, a weaker statement, according to which in each possible world where Kant exists longer than $X$ there is a moment in which he has a brain, is also not true. It seems to be logically - and probably also physically - 
possible to prolong the early brainless stage of Kant's development for an indefinite amount of time.

A more promising idea is to develop a "two-dimensional" possible worlds framework, in which properties are possessed not just in a given world but in a world at a given time. Then, it can be stated that a property $\mathrm{F}$ of an object $x$ is prospectively necessary if and only if for every moment $t$ in every world in which $x$ exists, $x$ has $\mathrm{F}$ at every moment later than $t$. However, such solution has an important drawback. The crucial idea of our paper is that an object can change its nature by changing the modal status of its properties. Unfortunately, the above solution does not leave a space for expressing that, for example, a property $\mathrm{F}$ is merely contingent for an object $x$ at one moment but then starts to be prospectively necessary. It is so because while the definition of F's prospective necessity involves time it is not a definition of F's being prospectively necessary at a particular time.

To amend this problem another modification of possible worlds framework is needed, which introduces trans-world moments and an accessibility relation that connects certain worlds-times pairs (analogous to our "modal binding"). If some moments, like $t_{m}$ and $t_{n}$ where $t_{n}$ is earlier than $t_{m}$, can belong to many possible worlds, then it can be stated that $\mathrm{F}$ is prospectively necessary for $x$ at $t_{m}$ in world $W$ because in every possible world, accessible from $t_{m}$ in world $W$, in which $x$ and $t_{m}$ exists, $x$ has $\mathrm{F}$ at all moments later than $t_{m}$. Despite that $\mathrm{F}$ may be contingent for $x$ at $t_{n}$ in world $W$ due to the fact that not in all worlds, accessible from $t_{n}$ in world $W$, in which $x$ and $t_{n}$ exist, $\mathrm{F}$ is possessed by $x$ at all moments later than $t_{n}$. From this perspective, every maximal branch of a modal history of $x$ may be identified with a set of possible worlds which do not differ in respect of $x$ 's properties through time. However, such possible worlds framework assumes not only the possibility of identifying objects between possible worlds, which is problematic on its own grounds, but also the possibility of moments trans-world identification. The possible histories framework developed in this paper does not need any of these and utilizes only an intuitive idea that an object's lifetime could have been different from the actual one.

\subsection{Retrospective Necessity}

The necessity of "being an embryo" is a mirror image of the necessity connected with "having a brain" (at least in the context of Kant's life). Neither of these properties was possessed by Kant at every moment of his actual life. However, while it was impossible for Kant to lose his brain, the same does not hold about the property of being an embryo. In fact, the situation is reversed: it is possible that Kant is an embryo at some moment $t_{i}$ but does not have this property at later moments; but is it impossible that he is not an embryo at moments earlier than $t_{i}$.

In terms of the modal histories framework, we may state that at least at some moments of Kant's actual life it was "retrospectively necessary" for him to be an embryo, where retrospective necessity is defined as follows:

(D5) At any point $\mathrm{g}_{\mathrm{i}}$ belonging to $\mathrm{MH}(\mathrm{x})$ it is retrospectively necessary for $\mathrm{x}$ to have a property $F$ $\left(\square^{\leftarrow} F\left(g_{i}\right)\right)$ iff for every $\mathrm{g}_{\mathrm{k}}$ belonging to $M H(x)$, if $\mathrm{g}_{\mathrm{i}}$ is further than $\mathrm{g}_{\mathrm{k}}$, then object $\mathrm{x}$ possesses $F$ at $\mathrm{g}_{\mathrm{k}}$.

$\forall_{g_{i} \in M H(x)}\left(\square^{\leftarrow} F\left(g_{i}\right) \leftrightarrow \forall_{g_{k} \in M H(x)}\left(g_{k}<g_{i} \rightarrow F\left(g_{k}\right)\right)\right)$

The notion of retrospective necessity is a counterpart of the temporal logic operator H ("It has always been the case that ...", [17, p. 32]), where $H p$ is true at some moment if and only if $p$ is true at all earlier moments.

Similarly to case of prospective modalities, the notion of "retrospective possibility" can be characterized: 
(D6) At any point gi belonging to $\mathrm{MH}(x)$ it is retrospectively possible for $\mathrm{x}$ to have a property $F$ $\left(\diamond^{\leftarrow} F\left(g_{i}\right)\right)$ iff there is $\mathrm{g}_{\mathrm{k}}$ belonging to $M H(x)$ such that $\mathrm{g}_{\mathrm{i}}$ is further than $\mathrm{g}_{\mathrm{k}}$ and object $\mathrm{x}$ possesses $F$ at $\mathrm{g}_{\mathrm{k}}$.

$\forall_{g_{i} \in M H(x)}\left(\diamond^{\leftarrow} F\left(g_{i}\right) \leftrightarrow \exists_{g_{k} \in M H(x)}\left(g_{k}<g_{i} \wedge F\left(g_{k}\right)\right)\right)$

Again, it can be easily noticed that retrospective necessity entails retrospective possibility. ${ }^{2}$ What is more, as in the case of prospective necessity, retrospective necessity is weaker than absolute necessity. An object can possess a property in a retrospectively necessary way at some points its modal history without having this property at all points.

Going back to Kant's modal history, we should postulate that at some points, corresponding to certain stages of Kant's actual life, it was retrospectively necessary for him to be an embryo. In case of "having a brain" it is also plausible to assume that Kant could not possess this property without possessing it in a prospectively necessary way. We may ask if an analogous statement regarding "being an embryo" should also be accepted, i.e. whether it is true that, if at some point $g_{i}$ belonging to Kant's modal history, Kant possesses "being an embryo", then at $\mathrm{g}_{\mathrm{i}}$ it is retrospectively necessary for Kant to be an embryo.

It seems a little less intuitive to accept the above claim than its counterpart concerning "having a brain". This is because we may imagine that in some non-actual parts of Kant's modal history he develops beyond the embryonic stage but then, due to some science-fiction nanotechnology, is reversed to the earlier phase. If such scenarios are possible, then the modal (and so essential) status of "being an embryo" is not uniform across Kant's modal history and only in some parts of it is being an embryo possessed in a retrospectively necessary way.

The notion of retrospective necessity designates a third type of necessity, different from both absolute and prospective necessities, and so may be regarded as connected with yet another type of essential property. Such properties do not have to be possessed at every point of an object's modal history, but if they are possessed at some point, then they are possessed at all earlier points up to the starting moment of an object's existence. In other words, if an essential property is necessary in a prospective sense, it can be gained during the object's existence, but then cannot be lost before its end. Reversely, if an essential property is necessary in a retrospective sense, it can be lost during the object's existence, but the object could not exist without it at earlier moments.

\section{4. Relative Necessity}

The kind of necessity that was connected with "being a philosopher" in Kant's life seems to be even weaker than prospective and retrospective necessities. The property of being a philosopher can not only be gained at some moment later then the starting moment of an object's existence, but can also be lost before an object ceases to exist. Why then should we postulate that possessing such a property is necessary in any sense? It is necessary if, as is claimed in the earlier story concerning Kant, after gaining this property an object has to possess it for some period of time. Further, we will refer to this weak type of necessity as "relative necessity".

In terms of the modal histories framework the above idea can be expressed by stating that at some point an object possesses a property in a relatively necessary way if and only if it has this property at all further points in some range. To characterize the notion of "relative necessity" more precisely, we will need to define a concept of the "upper-limiting set of points of $\mathrm{MH}(\mathrm{x})$ " and "lower-limiting set of points of $\mathrm{MH}(\mathrm{x})$ ":

(D7) $G_{t_{j} U P}^{x}$ is a upper-limiting set of points of a $M H(x)$ if and only if elements of $G_{t_{j} U P}^{x}$ are all points of $M H(x)$ whose second element is earlier or equal to $t_{j}\left(e . g .\left\langle A, t_{j}\right\rangle\right.$, $\left.<B, t_{j-1}>\right)$ and only those points. 
$G_{t_{j} L O W}^{x}$ is a lower-limiting set of points of a $M H(x)$ if and only if elements of $G_{t_{j} L O W}^{x}$ are all points of $M H(x)$ whose second element is later or equal to $t_{j}\left(\right.$ e.g. $\left.\left\langle A, t_{j}\right\rangle,\left\langle B, t_{j+1}\right\rangle\right)$ and only those points.

By using the notions presented in (D7), relative necessity can be defined. However, the situation is a bit more complicated, as there is more than one type of relative necessity. First, there is "prospective relative necessity", which occurs at some point of a modal history if and only if an object has to possess a property up to a certain further point. Second, we can distinguish "retrospective relative necessity", which occurs at some point of a modal history if and only if an object has to possess a property up to a certain earlier point. Third, both prospective and retrospective types of relative identity come in different versions connected with the temporal distance between a point at which it is relatively necessary to possess a property and the point up to which this property has to be possessed. Due to these complications we may provide two general definitions of "relative prospective necessity" and "relative retrospective necessity":

(D8) At any point $\mathrm{g}_{\mathrm{i}}$ belonging to $\mathrm{MH}(\mathrm{x})$ it is relatively prospectively necessary for $\mathrm{x}$ to have a property $F\left(\square_{R} F\left(g_{i}\right)\right)$ iff there is $G_{t_{j} U P}^{x}$ such that if a point $\mathrm{g}_{\mathrm{k}}$ belongs to $G_{t_{j} U P}^{x}$ and $\mathrm{g}_{\mathrm{k}}$ is further than $\mathrm{g}_{\mathrm{i}}$, then object $\mathrm{x}$ possesses $F$ at $\mathrm{g}_{\mathrm{k}}$.

$\forall_{g_{i} \in M H(x)}\left[\square_{R} F\left(g_{i}\right) \leftrightarrow \exists_{v \subset M H(x)}\left(G_{t_{j} U P}^{x}(v) \wedge \forall_{g_{k}}\left(g_{k} \in v \wedge g_{i}<g_{k} \rightarrow F\left(g_{k}\right)\right)\right)\right]$

(D9) At any point $\mathrm{g}_{\mathrm{i}}$ belonging to $\mathrm{MH}(\mathrm{x})$ it is relatively retrospectively necessary for $\mathrm{x}$ to have a property $F\left(\square_{R}^{\leftarrow} F\left(g_{i}\right)\right)$ iff there is $G_{t_{j} L O W}^{x}$ such that if a point $\mathrm{g}_{\mathrm{k}}$ belongs to $G_{t_{j} L O W}^{x}$ and $\mathrm{g}_{\mathrm{k}}$ is earlier than $\mathrm{g}_{\mathrm{i}}$, then object $\mathrm{x}$ possesses $F$ at $\mathrm{g}_{\mathrm{k}}$.

$\forall_{g_{i} \in M H(x)}\left[\square_{R} F\left(g_{i}\right) \leftrightarrow \exists_{v \subset M H(x)}\left(G_{t_{j} L O W}^{x}(v) \wedge \forall_{g_{k}}\left(g_{k} \in v \wedge g_{i}>g_{k} \rightarrow F\left(g_{k}\right)\right)\right)\right]$

Of course, two corresponding notions of "relative prospective possibility" and "relative retrospective possibility" may also be defined:

(D10) At any point $\mathrm{g}_{\mathrm{i}}$ belonging to $\mathrm{MH}(\mathrm{x})$, it is relatively prospectively possible for $\mathrm{x}$ to have a property $F\left(\diamond_{R} F\left(g_{i}\right)\right)$ iff there is $G_{t_{j} U P}^{x}$ such that there is a point $\mathrm{g}_{\mathrm{k}}$ that belongs to $G_{t_{j} U P}^{x}$ and $\mathrm{g}_{\mathrm{k}}$ is further than $\mathrm{g}_{\mathrm{i}}$ and object $\mathrm{x}$ possesses $F$ at $\mathrm{g}_{\mathrm{k}}$.

$\forall_{g_{i} \in M H(x)}\left[\diamond_{R} F\left(g_{i}\right) \leftrightarrow \exists_{v \subset M H(x)}\left(G_{t_{j} U P}^{x}(v) \wedge \exists_{g_{k}}\left(g_{k} \in v \wedge g_{i}<g_{k} \wedge F\left(g_{k}\right)\right)\right)\right]$

(D11) At any point $\mathrm{g}_{\mathrm{i}}$ belonging to $M H(x)$ it is relatively retrospectively possible for $\mathrm{x}$ to have a property $F\left(\diamond_{R}^{\leftarrow} F\left(g_{i}\right)\right)$ iff there is $G_{t_{j} L O W}^{x}$ such that there is a point $\mathrm{g}_{\mathrm{k}}$ that belongs to $G_{t_{j} L O W}^{x}$ and $\mathrm{g}_{\mathrm{k}}$ is earlier than $\mathrm{g}_{\mathrm{i}}$ and object $\mathrm{x}$ possesses $F$ at $\mathrm{g}_{\mathrm{k}}$.

$\forall_{g_{i} \in M H(x)}\left[\diamond_{R} F\left(g_{i}\right) \leftrightarrow \exists_{v \subset M H(x)}\left(G_{t_{j} L O W}^{x}(v) \wedge \exists_{g_{k}}\left(g_{k} \in v \wedge g_{i}>g_{k} \wedge F\left(g_{k}\right)\right)\right)\right]$

Analogously, as in the case with other types of necessity, here relative possibilities are also entailed by respective relative necessities. What is more, the relative necessity is the weakest form of necessity. First, if at some point it is absolutely necessary to possess a property, then at this point it is both prospectively and retrospectively relatively necessary to possess this property. Second, possessing a property in a prospectively necessary way entails that it is possessed relatively 
prospectively necessary. Finally, possessing a property in a retrospectively necessary way entails that it is possessed relatively retrospectively necessary.

If the earlier story about Kant's life is true, then at some points of his modal history it is relatively prospectively necessary for him to be a philosopher. However, it is very unlikely that at each point at which he is a philosopher it is relatively prospectively necessary for him to possess this property. In this case "being a philosopher" may be relatively necessary at some parts of Kant's modal history, but at other parts this property may not be connected even with this weakest type of necessity.

So far we have characterized four general variants of necessity, which may correspond with four distinct types of essential properties. Essential properties that are absolutely necessary are possessed by an object at every point of its modal history. In Kant's case, "being a homo sapiens" seems to be a legitimate candidate. Prospective necessity is connected with essential properties that can be gained during an object's existence, but then cannot be lost up to its end. It seems plausible that if Kant has a brain at some point in his modal history, then at this point it is prospectively necessary for him to possess a brain. Retrospective necessity is a mirror image of prospective necessity. It is connected with essential properties that can be lost at some point of existence, but nevertheless have to be possessed at all earlier moments. We argued that there are some points in Kant's modal history at which "being an embryo" is for him necessary in a retrospective way. Finally, relative necessity designates a class of essential properties that may be gained at some point and then lost at a later time. Despite this, they may be characterized as necessary because they display a "modal inertia". For example, in case of relative prospective necessity, they cannot be lost for some period of time. It may be the case that "being a philosopher" is relatively necessary for Kant at some points in his modal history.

\section{Puzzles Reconsidered}

Now we are ready to turn back to the examples introduced at the beginning of this paper. approach. We believe that the above-proposed conceptual framework may help to clarify these puzzling cases of dynamic essences in sociology, theology, and biology.

\subsection{Social Internalization}

The simplest case is the process of social internalization. During primary socialization a socially constructed image of the world becomes a part of individual identity. One cannot lose this without losing one's own personal integrity. That is why in the case of internalization it can be said that some accidental social properties become essential for individual human beings.

This process can be simply characterized with a help of the introduced concepts. As is clear from the discussion on Kant, being human involves a complex combination of different kinds of modalities. First of all, all humans presumably have some absolute necessary properties. Perhaps being a material substance or being a rational animal are examples of such properties. These constitute what is called 'nature' in classical essentialism. We might denote such absolute necessary properties as $\left\{\square^{A} P\right\}$.

Now, humans are, however, amazingly flexible entities. The same absolute nature might be joined with different cultural extensions. Thus, second, in the early stages of its, a human has many different prospective possibilities. A child could be raised in this or that culture, could internalize this or that image of the world, and could therefore act in this or that way. At the beginning the modal properties of humans, besides some absolute necessary properties $\mathrm{P}$, also embrace many prospective possible properties Q: $\{\diamond \rightarrow Q\}$.

Suppose now that a child was raised in a determinate culture, and acquired its first language and internalized some primary world-view. After successful primary socialization, something has essentially changed. Now we have no more tabula rasa, but rather tabula scripta, at least partly. Some possibilities allowed in the first stage have been realized and now determine the modal status 
of the individual in a new way. According to Berger and Luckmann, as quoted above, the process of primary socialization is irreversible. Once one acquires a social identity, one cannot lost it without a crisis of identity and even mental pathology. It seems therefore that this is a case of prospective necessity: $\left\{\square^{\rightarrow} R\right\}$.

Usually, however, the modal determination in not so all-embracing. After successful primary socialization a human being could choose many different forms of secondary socialization. A child can still become a firefighter, doctor, or philosopher, even though it cannot reverse the process through which it became a child of a determinate culture. These secondary social roles are important for one's identity, but not in such a deep existential way as one's primary image of the world. This is because they are perceived as accidental. Even the child feels that it could become somebody completely different. This means that a human being, after primary socialization, achieves a new set of prospective possibilities: $\left\{\diamond^{\rightarrow} S\right\}$.

The whole process of primary socialization might be therefore described as a transition from a one modal stage to another. It might be depicted in the following way:

$\left\{\square^{A} P, \diamond \rightarrow Q\right\} \rightarrow\left\{\square^{A} P, \square^{\rightarrow} R, \diamond \rightarrow S\right\}$

The absolute essences remain unchanged; new prospective-essential properties are achieved; the prospective possibilities are accordingly changed. This is the same human who passed through primary socialization, but she acquires a new nature.

\section{2. The History of Salvation}

Saving humankind is more complicated that raising a child. According to St. Augustine, human salvation does not consist in simple essentialization, as primary socialization does, but also in a series of modally relative essentializations and de-essentializations, which were not allowed in the former sociological case. Moreover, in this case we are faced with true objective modalities; psychological integrity is not at stake here, as in the previous case, but the very existence of an individual, just as in classical essentialism.

At the beginning everything was possible, leaving aside the presupposed absolute essence of humankind. Humans in Eden could sin or not sin. Perhaps the first human thought that these were prospective modalities, but they turned out to be relative only: $\left\{\diamond_{R} S, \diamond_{R} \neg S\right\}$.

This modal status quo changed after the first realization of the possibility of sinning. It turned out that the first sin was a modal trap. After the Fall, humankind could not not sin. If that were the end of the story, humankind would be eternally condemned to sinning. Again, afterwards it turned out this was not a prospective modality, which would exclude any form of salvation, but only a relative one: $\left\{\square_{R} S\right\}$, that is: $\left\{\neg \diamond_{R} \neg S\right\}$.

The Redemption was apparently a reversion of this modal essentialization. Christ's resurrection restored the previous modal status of humankind. The difference between humankind before the Fall and humankind after the Redemption lies, however, not only in their previous experiences. Now humankind can again sin or not sin, but this time the realization of the possibility of sin does not, as it seems, lead to a modal trap. It is plausible then to replace the relative possibility of not sinning with prospective possibility: $\left\{\diamond_{R} S, \diamond \rightarrow \neg S\right\}$. After the Redemption, we always retain the possibility of making good things.

The final Salvation, according to Augustine, is the exclusion of the possibility of sin. It is something like the inversion of the Fall. After the Fall, humankind could not not sin, whereas after the Salvation it cannot sin. Salvation, therefore, is an essentialization of sancticity. It seems that this modal shift should be thought not as relative, but as prospective: $\left\{\square^{\rightarrow} \neg S\right\}$, in other words: $\left\{\neg \diamond^{\rightarrow} S\right\}$.

Therefore Augustine's theological history of creation, the Fall, the Redemption, and Salvation of humankind is a complicated story of relative essentialization and de-essentialization of sins and virtues: 


$$
\left\{\diamond_{R} S, \diamond_{R} \neg S\right\} \rightarrow\left\{\neg \diamond_{R} \neg S\right\} \rightarrow\left\{\diamond_{R} S, \diamond \rightarrow \neg S\right\} \rightarrow\{\neg \diamond \rightarrow S\}
$$

Its final result is the necessitation of the former mere possibility to not sin. This general process, however, was interrupted by the relative essentialization of $\sin$ and its prospective deessentialization. It seems that the proposed conceptual framework might really be adopted to clarify these complicated matters.

\section{3. Jellyfish Life}

Now we can turn to the most complicated case of $T$. nutricula jellyfish life. The description of a standard jellyfish life cycle, presented by Piraino et al. [15], suggest that the life of a jellyfish consists in three phases, during which its essential properties change. First, a jellyfish starts its life as a larva and stays in this form for a certain period of time. Second, it transforms from a larva to a polyp and also possesses this form for some time. Finally, it changes from polyp to an adult medusa. This final stage lasts till the end of the organism's life. However, the life cycle of $T$. nutricula seems to be special, since this jellyfish is able to revert from the adult stage to the polyp stage, and then again become an adult in a potentially infinite cycle.

Similarly to a "standard" jellyfish, T. nutricula starts its existence in larval form. This means that at all the minimal points of its modal history, it possesses "being a larva". What is more, it has to remain in a larval stage at a certain number of later moments. Because of this, at early points of a modal history, it is retrospectively necessary for $T$. nutricula to be a larva since it has this property at all earlier points up to the minimal ones. In addition, at these early points it is also relatively prospectively necessary to be a larva, due to the fact that this property cannot be lost for a certain period of time. We may state that in the early phases of life T. nutricula has the following set of essential properties: $\left\{\square^{A} G, \square^{\leftarrow} L, \square_{R} L\right\}$, where $L$ designates "being a larva" and $G$ symbolizes all absolutely necessary properties which have to be possessed by $T$. nutricula.

However, it is not the case that at all points of a modal history the set of T. nutricula's essential properties equals $\left\{\square^{A} G, \square^{\leftarrow} L, \square_{R} L\right\}$. At some distance from the minimal point of a modal history, there are two points $g_{i}$ and $g_{k}$ such that $g_{k}$ is a successor of $g_{i}$ (i.e., they stand in a modal binding relation), and at $g_{i}$ the jellyfish is a larva but at $g_{k}$ it is a polyp. Such a situation has to occur within a modal history if it is possible for T. nutricula to transform from the larval stage into a polyp. Then, at point $g_{i}$ it is no longer relatively prospectively necessary to be a larva, as at one of the successive moments the jellyfish is a polyp. Nevertheless, at $g_{i}$ it is still retrospectively necessary to be a larva, since a jellyfish is a larva at all earlier moments. Because of this, the set of essential properties shrinks to: $\left\{\square^{A} G, \square^{\leftarrow} L\right\}$.

What is more, a set of essential properties undergoes another modification as soon as $T$. nutricula becomes a polyp. As was stated above, in the modal history of T. nutricula there is a point $g_{i}$ at which the jellyfish is a larva and a successive point $g_{k}$ at which it possesses "being a polyp". According to a biological story, a jellyfish has to be a polyp for some time after acquiring this property. This means that at point $g_{k}$ it is relatively prospectively necessary for a jellyfish to be a polyp. Nevertheless, at this point it is still retrospectively necessary for it to be a larva, as a jellyfish is a larva at all earlier points. Because of this, between $g_{i}$ and $g_{k}$ the set of essential properties expands to the following form: $\left\{\square^{A} G, \square^{\leftarrow} L, \square_{R} P\right\}$, where P designates "being a polyp".

The above stage is very short and the set of essential properties changes again just after point $g_{k}$. If at $g_{k}$ it is relatively prospectively necessary to have "being a polyp", then at all successive points a jellyfish is a polyp. However, at these points it is no longer retrospectively necessary for a jellyfish to be a larva, because there is an earlier point, i.e. the point $g_{k}$, at which it is not a larva but a polyp. Due to this fact at points further than $g_{k}$ the set of essential properties shrinks again to the form $\left\{\square^{A} G, \square_{R} P\right\}$.

A jellyfish may transform once again during its lifetime, this time from a polyp to an adult medusa. If this is the case, then again in its modal history there is a point $g_{m}$ at which it is a polyp and a successive point $g_{n}$ at which it is an adult medusa. Points such as $g_{m}$ designate another 
modification of essential properties. At $g_{m}$ it is no longer relatively prospectively necessary to be a polyp, due to the presence of the successive point $g_{n}$. Because of this, only those properties that are necessary in an absolute way belong to the set of essential properties possessed at $g_{m}:\left\{\square^{A} G\right\}$.

The further modification of the set of essential properties occurs at the first point at which a jellyfish is an adult medusa (such as the point $g_{n}$ characterized above). In the case of a "standard" life cycle, a jellyfish has to possess the property of being an adult medusa up to the end of its life and so at each point at which a jellyfish possesses this property, it possesses it in a prospectively necessary way $\left\{\square^{\rightarrow} M\right\}$ (M designates "being an adult medusa").

However, in the special life cycle of $T$. nutricula, the set of essential properties $\left\{\square^{A} G, \square_{R} P\right\}$ can shrink to $\left\{\square^{A} G\right\}$ just before the possibility of becoming an adult medusa arises, and then, if the property of being an adult medusa is acquired, change to $\left\{\square^{A} G, \square_{R} M\right\}$, instead of $\left\{\square^{A} G, \square^{\rightarrow} M\right\}$, known from the "standard" life cycle. Further, when in a successive moment there is the possibility to return to the polyp stage, the set shrinks again to $\left\{\square^{A} G\right\}$, and then, if the reversal from the adult stage to the polyp stage occurs, the set is again $\left\{\square^{A} G, \square_{R} P\right\}$. While it is unlikely, it is possible for such a cycle to repeat infinitely in the life of a particular T. nutricula. Overall, the pattern of changes in the essential properties within the life of a $T$. nutricula can be presented as a sequence of sets that ends with a loop:

$$
\begin{aligned}
& \left\{\square^{A} G, \square^{\leftarrow} L, \square_{R} L\right\} \rightarrow\left\{\square^{A} G, \square^{\leftarrow} L\right\} \rightarrow\left\{\square^{A} G, \square^{\leftarrow} L, \square_{R} P\right\} \rightarrow\left\{\square^{A} G, \square_{R} P\right\} \\
& \leftarrow \rightarrow\left\{\square^{A} G,\right\} \leftarrow \rightarrow\left\{\square^{A} G, \square \square_{R} M\right\}
\end{aligned}
$$

The framework of modal histories used here thus makes possible an account of the changing essences of biological organisms. T. nutricula seems to both lose (e.g., "being a larva") and gain (e.g., "being a polyp") essential properties during its life.

\section{Conclusion}

In this paper we attempted to combine modality and time in a new way. Traditionally modalities are thought to be timeless. Classical necessities and possibilities hold for any time when an individual exists. We believe that such approach cannot do justice to the common phenomena of development.

Some changes really involve a modification of the modal status of a thing, but nevertheless do not lead to its destruction. It is, after all, the same child that was born and raised in a determinate culture, the same humankind that fell and was saved, and finally the same jellyfish that pass through all the stages of their life-cycle. All these changes involve a deep modal shift: some things that were possible become necessary, and vice versa. In other words, they are examples of real essential change. These cases, to our minds, challenge the traditional view of static essences.

We propose dissolving the close connection between modality and time and unite them in new ways. We distinguished four such ways: absolute, prospective, retrospective, and relative modalities. Classical cases turned out to be simply extreme points of a large range of modalities. We tried to show that such simple modifications make possible a clarification of some puzzling real examples from sociology, theology, and biology.

One common charge against classical essentialism is that it excludes the real development of things. Ancient static essences, it is said, are incompatible with the contemporary dynamic vision of the world. On the other hand, modern anti-essentialists are accused of neglecting the real modal constraints that determine the process of development. Clearly not everything might really become something else, or not always. We believe that both sides of this discussion are right and we hope that our investigation shows the way in which these two opposite views might be reconciled.

\section{Acknowledgments}

This publication was generously supported by a grant from the National Science Center, Poland, No. 2013/11/D/HS1/04332. 


\section{References}

1. Augustine. On Reprimand and Grace, In On the Free Choice of the Will, On Grace and Free Choice, and Other Writings, Cambridge: Cambridge University Press, 2010.

2. Bennet, D. Essential Properties, The Journal of Philosophy, 66, 1969, pp. 487-499.

3. Berger, P. L. \& T. Luckmann. The Social Construction of Reality. A Treatise in the Sociology of Knowledge, Harmondsworth: Penguin Books, 1966.

4. Brody, B. A. Towards an Aristotelian Theory of Scientific Explanation, Philosophy of Science, 39, 1972, pp. 20-31.

5. Brody, B. A. Identity and Essence, Princeton: Princeton University Press, 1980.

6. Chandler, H. S. Essence and Accident, Analysis, 26, 1966.

7. Copi, I. Essence and Accident, The Journal of Philosophy, 51, 1954, pp. 706-719.

8. Fine, K. Essence and Modality, Philosophical Perspectives, 8, 1994, pp. 1-16.

9. Kung, J. Aristotle on Essence and Explanation, Philosophical Studies, 31, 1976, pp. 361-383.

10. Matthews, G. B. Aristotelian Essentialism, Philosophy and Phenomenological Research, 50, 1990, pp. 251-262.

11. Mackie, P. Sortal Concepts and Essential Properties, The Philosophical Quarterly, 44, 1994, pp. 311-333.

12. Marcus, R. B. Essential Attribution, The Journal of Philosophy, 68, 1971, pp. 187-202.

13. Müller, T. Branching in the landscape of possibilities, Synthese, 188, 2012, pp. 41-65.

14. Owens, J. The Doctrine of Being in the Aristotelian Metaphysics, Toronto: Pontifical Institute of Mediaeval Studies, 1978.

15. Piraino, S., Boero, F., Aeschbach, B., \& Schmid, V. Reversing the Life Cycle: Medusae Transforming into Polyps and Cells Transdifferentiation in Turritopsis Nutricula (Cnidaria, Hydrozoa), The Biological Bulletin, 190, 1996, pp. 302-312.

16. Porphyry. Introduction, Oxford: Clarendon Press, 2003.

17. Prior, A. Past, Present, and Future, Oxford: Clarendon Press, 1967.

18. Robertson, T. \& P. Atkins, Essential vs. Accidental Properties, In E. N. Zalta (ed.), The Stanford Encyclopedia of Philosophy, Winter 2013, http://plato.stanford.edu/archives/win2013/entries/essential-accidental/

19. Rorty, A. O. Essential Possibilities in the Actual World, The Review of Metaphysics, 25, 1972, pp. 607-624.

20. Teller, P. Essential Properties: Some Problems and Conjectures, The Journal of Philosophy, 72, 1975, pp. 233-248.

21. Thomasson, R. H. Combinations of Tense and Modality, In D. Gabbay \& F. Guenthner (eds.), Handbook of Philosophical Logic, vol. 2, Dordrecht: D. Reidel Publishing Company, 1984, pp. 135-165.

22. Torza, A. Speaking of Essence, The Philosophical Quarterly, 65, 2015, pp. 211-231.

23. Zalta, E. N. Essence and Modality, Mind, 459, 2006, pp. 659-693.

\section{Notes}

1. The maximal points of a modal history, i.e. points after which there are no further points, constitute an exception. According to (D3) and (D4), at maximal points everything is prospectively necessary but nothing is prospectively possible.

2. The minimal points of a modal history, i.e. points that have no earlier points, constitute an exception. According to (D5) and (D6), at minimal points everything is retrospectively necessary but nothing is retrospectively possible. 